\title{
Macroscopic and Histological Variations in the Cellular Tapetum in Dogs
}

\author{
Yasuhiro YAMAUE ${ }^{1,2)}$, Yoshinao Z. HOSAKA ${ }^{1)}$ and Masato UEHARA ${ }^{1) *}$ \\ 1) Department of Veterinary Anatomy, Faculty of Agriculture, Tottori University, Tottori 680-8553, Japan \\ ${ }^{2)}$ Department of Basic Veterinary Science, The United Graduate School of Veterinary Science, Yamaguchi University, Yamaguchi \\ 753-8515, Japan
}

(Received 12 March 2014/Accepted 8 April 2014/Published online in J-STAGE 30 April 2014)

\begin{abstract}
We aimed to document macroscopic variations in the cellular tapetum in the dog, to provide a histologic description of the macroscopic results and to evaluate the correlation between the macroscopic appearance and aging. Fifty three dogs including 5 beagles, 1 Chihuahua and 47 mixed breeds of each gender were used. For a macroscopic study, the fresh tapetal fundi were photographed using digital camera. For a histological study, the glutaraldehyde-formalin fixed eyes were embedded in nitrocellulose and stained with hematoxylineosin or thionine. The normal tapetum was triangular with the rounded angles and the smooth contour. The atypical tapetum was smaller and more variable in shape, contour and color than the normal one. In severe cases, the fundus was devoid of the tapetum. The atypical tapetum tended to increase in frequency with aging. Retinal pigment epithelial cells on the normal tapetum were unpigmented. In the eye with the atypical tapetum, regardless of tapetal size and shape, unpigmented retinal pigment epithelial cells showed a similar distribution to that on the normal tapetum, even in a dog without a tapetum. Although there is a congenitally hypoplastic tapetum, the atypical tapetum tends to increase in incidence and severity with aging.

KEY WORDS: aging, canine, cellular tapetum, retinal pigment epithelial layer
\end{abstract}

doi: 10.1292/jvms.14-0132; J. Vet. Med. Sci. 76(8): 1099-1103, 2014

Eyeshine in a number of vertebrates including carnivores is a phenomenon of light reflection from the tapetum lucidum of the eyes. The tapetum is thought to reflect light back to the retina, thus enhancing scotopic sensitivity. It is interposed between the choroid capillary layer beneath the retinal pigment epithelial layer (RPEL) and the choroidal proper substance. In the tapetal area, the RPEL lacks pigment so that the tapetum can be clearly seen through the retina [15]. A cellular tapetum is characteristic of carnivores and composed of multiple layers of cells arranged in a bricklike structure. The most striking feature of tapetal cells in the dog as observed by electron microscopy is the presence of numerous slender, electron-dense rods in a regular array in the cytoplasm [13]. The tapetum of the dog eye is triangular in outline with the base of the triangle being ventral. The tapetum occupies the upper half of the ocular fundus. The form and color of the tapetum are variable in dogs $[4,9,11,16,26]$. In general, small-sized breeds including the Yorkshire Terrier and Chihuahua have a significantly smaller tapetal area. Some dogs congenitally lack the tapetum entirely, especially in Labrador retrievers and beagles of certain families. Furthermore, the tapetum is small in area in the subalbinotic fundus and completely absent in the albinotic fundus [1, 2, 9-11, 16]. Wyman and Donovan [26] state that beadiness refers to the mosaic pattern observed at

*Correspondence to: Uehara, M., Department of Veterinary Anatomy, Faculty of Agriculture, Tottori University, Tottori 680-8553, Japan. e-mail: muehr@ncn-t.net (C)2014 The Japanese Society of Veterinary Science

This is an open-access article distributed under the terms of the Creative Commons Attribution Non-Commercial No Derivatives (by-nc-nd) License $<$ http://creativecommons.org/licenses/by-nc-nd/3.0/>. the periphery of the tapetum and is most easily seen near the junction of the tapetum and the non-tapetal area. The degree of beadiness increases with the age, a phenomenon that is more apparent in small dog breeds. These previous studies have provided little histological examination of variability in the tapetum.

In this study, we aimed to document macroscopic variations in the canine tapetum, to provide a histological description of the macroscopic results and to evaluate the correlation between the macroscopic appearance and aging.

\section{MATERIALS AND METHODS}

Eyes were obtained from 53 dogs including 5 beagles (2-3 years old), 1 Chihuahua (10 years old) and 47 mixed breeds (1 to 13 years old) of each gender that were euthanized by carbon dioxide overdose (47 mixed breeds) or deep anesthesia using pentobarbital sodium $(100 \mathrm{mg} / \mathrm{kg}$, i.p.) (the other 6 dogs) for an unrelated experiment to the eye by other group in our faculty. Both eyes of all animals were removed within $2 \mathrm{hr}$ of death. For a macroscopic study (all cases), the unilateral eyes were cut along the equatorial plane, and the tapetal fundus was photographed by digital camera (EXZ400, Casio, Tokyo, Japan). For a histological study (20 cases including 5 beagles, 1 Chihuahua and 18 mixed breeds), following macroscopic observations, the unilateral eyes were injected with 3\% glutaraldehyde in $10 \%$ formalin into the vitreous cavity. After fixation, the posterior cup of each eye was dehydrated, embedded in nitrocellulose (Collodion, Wako, Osaka, Japan), cut at 30-40 $\mu \mathrm{m}$ and then stained with hematoxylin-eosin or thionine. In 5 beagles, $40-\mu$ m sections of tapetum with the retina and choroid were cut at 0.5 to $2 \mathrm{~mm}$ intervals and reconstructed after measurement of the 
tapetum thickness and observations of the RPEL. These procedures were carried out in accordance with the guidelines of the Ethical Committee of Tottori University, Japan.

\section{RESULTS}

Macroscopic observations: The normal tapetum was triangular with rounded angles and smooth contour. Its base had usually contact with the optic nerve disc (OD), but separated from the OD in rare cases. Its apex located dorsally to the OD. The nasal half was longer than the temporal half in width. Thus, the nasal angle of the tapetum was more acute than the temporal angle. The color tone of the tapetum was not even; its center was brightest (Fig. 1). Based on histological observation, the color tone of the tapetum reflected the thickness of the tapetal tissue.

The atypical tapetum was smaller and more variable in shape, contour and color than the normal one (Fig. 2). The atypical tapetum disappeared from the periphery, especially from the nasal and ventral parts. In mild cases, the atypical tapetum was irregular in contour and faded in the nasal part (Fig. 2a). In severe cases (the Chihuahua), the fundus was devoid of the tapetum and had a reddish-brown area that was similar in both location and extent to the normal tapetum (Fig. 2d).

Bilateral differences in appearance of the tapetum were few through the normal and atypical tapeta.

Regarding the relationship of the atypical tapetum to age, the occurrence ratio was $31 \%$ in the atypical tapetum and $69 \%$ in the normal tapetum in dogs under age 5 (35 cases) and was $72 \%$ in the atypical tapetum and $28 \%$ in the normal tapetum in dogs over age 6 (18 cases). The tapetum tended to be atypical with increasing age. Furthermore, the atypical tapetum tended to increase in severity with aging.

Histological observations: In the normal tapetum, the RPEL was almost unpigmented on the tapetum (Fig. 3). The narrow peripheral zone of the tapetum was covered by the lightly pigmented RPEL. Thus, the distribution of tapetal tissue closely corresponded to the area of the macroscopic tapetum. The tapetum was thick in its central part, and its thickest part was located dorso-temporally to the OD (Fig. 4). The thickest part of the typical tapetum varied in thickness, from 20 to $70 \mu \mathrm{m}$ (average: $53 \mu \mathrm{m}$, standard deviation: $17 \mu \mathrm{m}$ ) and consisted of maximum 20 layers of tapetal cell.

In the atypical cases, in which the tapetum was markedly small and very irregular in contour, the tapetum was very thin. In these cases, the choroid was fully pigmented, the same as the normal choroid. Regardless of the shape of the atypical tapetum, the unpigmented RPEL showed a similar extent to that in the normal tapetum. Pigmentation of the choroid and pigmented RPEL was normal in all cases (Fig. 5). While the Chihuahua dog macroscopically lacked the tapetum, unpigmented RPEL showed histologically a similar distribution to that in the normal tapetum (Fig. 6a). Tapetal tissue was observed in a fragmentary fashion (Fig. 6b).

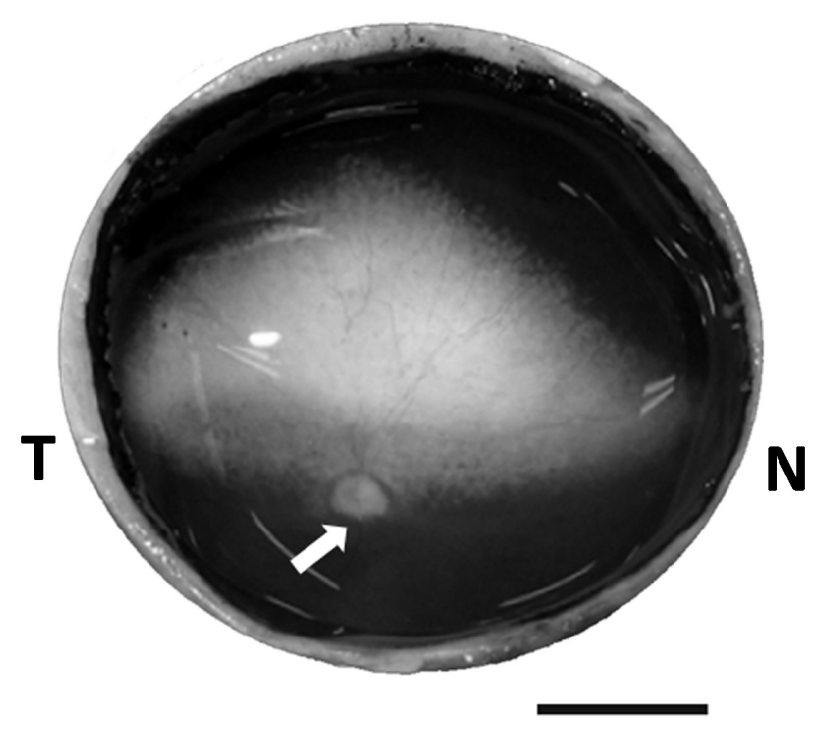

Fig. 1. The normal tapetum is almost triangular with rounded angles and smooth contour usually contacting with the optic nerve disc (arrow). Brightness of the tapetum reflects the thickness in tapetal tissue. $\mathrm{N}$, nasal; $\mathrm{T}$, temporal. Bar $=5 \mathrm{~mm}$.

\section{DISCUSSION}

A wide variation in extent and color of the tapetum has been reported in normal dogs $[9,11,16]$. The tapetum is poorly developed in the toy breeds including the Chihuahua and in dogs with a merle coat color $[11,16]$. Pigmentation of the choroid correlates closely with the development of the tapetum $[10,11]$. Interestingly, the albino ferret and the Siamese cat lack choroidal pigmentation, but have the tapetum $[22,23]$. According to Thibos et al. [22], the choroid in the Siamese cat contains melanocytes, but is defective in pigment production. Thus, the Siamese is completely free from pigment in the choroid but has the tapetum, because tapetal cells derive from neural crest cells as well as choroidal melanocytes. The blue-eyed white cat has no tapetum and no choroidal pigmentation, because neural crest cells do not migrate into the choroid. All cases observed in this study were normal in pigmentation of the choroid. In this study, unpigmented RPEL was equally distributed in the dog retina regardless of the extent and shape of the tapetal area. In the Chihuahua, the tapetum was not found, but the unpigmented RPEL was similar in distribution to that of the normal tapetum.

The canine tapetum develops after birth [11, 17]. The developmental relation of the unpigmented RPEL to the tapetum has not been studied in dog. According to a study of the bovine eye, the adult pattern of pigmented RPEL in nontapetal zones and unpigmented RPEL in the presumptive tapetal zone is well established in the early stage of pregnancy [7]. In other word, the extent of the unpigmented RPEL is decided before the development of the tapetum. Thus, compartmentalization of unpigmented and pigmented RPEL would not be directly related to the development or 

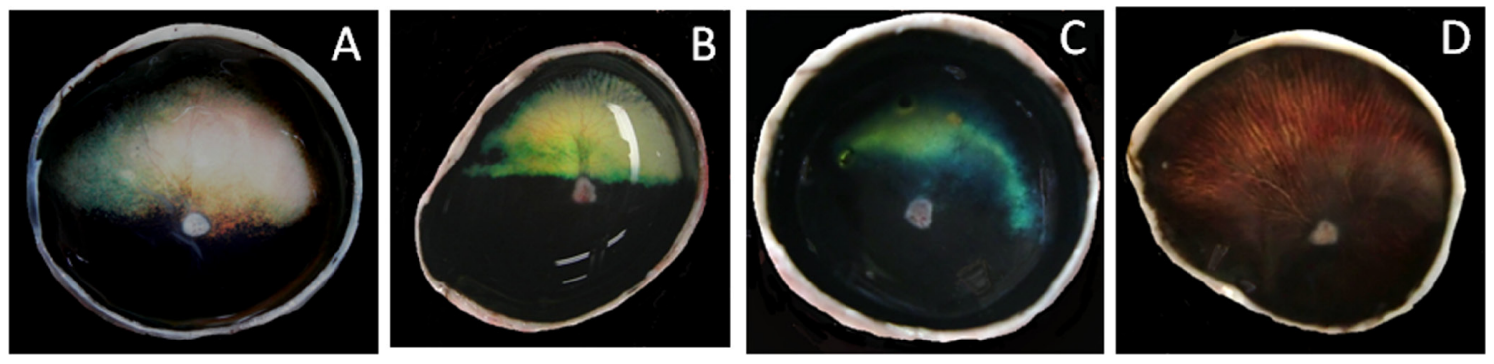

Fig. 2. The atypical tapetum showing variable shape and irregular contour. The tapetal area decreases from the nasal and ventral parts (left and ventral sides in each tapetum, respectively) of the tapetum (A-D). The Chihuahua dog (D) lacks the tapetum, and the dorsal part of its fundus is reddish-brown, which correspond approximately to the normal tapetal area both in location and size.

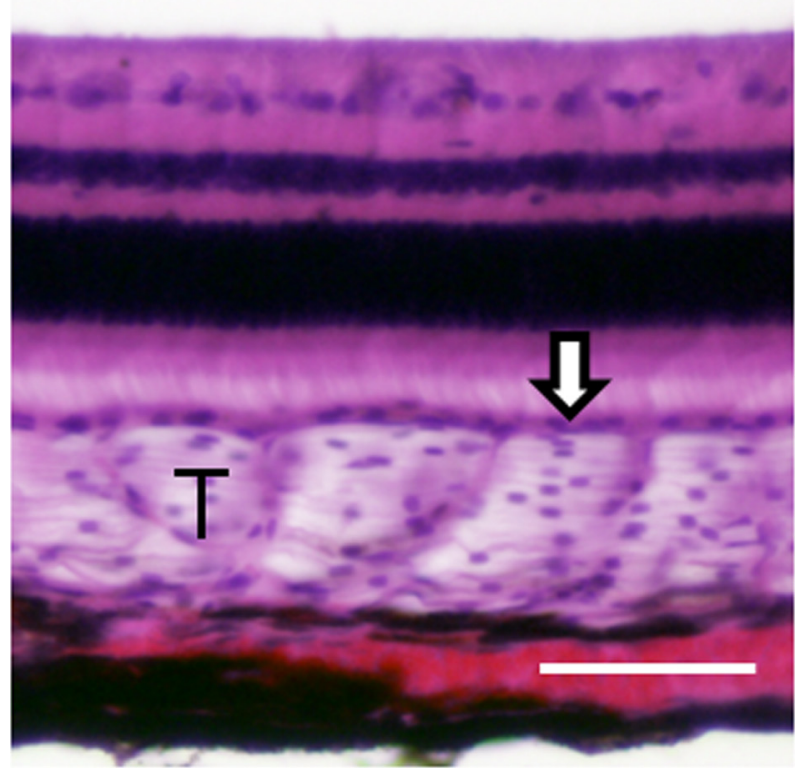

Fig. 3. The thickest part of the typical tapetum (T). The retinal pigment epithelial layer (arrow) on the tapetum is unpigmented. $\mathrm{Bar}=100 \mu \mathrm{m}$.

regression of the tapetum.

In this study, the atypical tapetum tended to increase in frequency with aging. Histologically, tapetal layers decreased in number throughout the atypical tapetum. Therefore, thin tapetal parts, namely the periphery of the tapetum, disappeared first, and the contour of the tapetum became irregular with shrinkage of the tapetum. According to Wyman and Donovan [26], the degree of beadiness of the tapetum increases with aging. Beadiness refers to the mosaic pattern observed in ophthalmoscopic examination at the periphery of the tapetum. Beadiness resulted from the irregular contour of the tapetum in this study. Thus, it is suggested that the tapetum in the dog tends to decrease in size macroscopically with aging as the number of tapetal cell layers decreases due to tapetal cell degeneration.

The atypical tapetum was found at high rates, especially

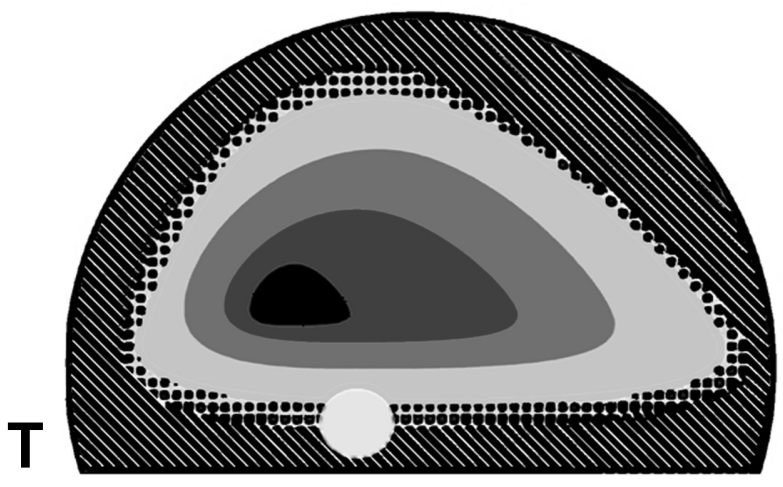

Fig. 4. Reconstructed topographic distribution of the tapetum thicknesses. The thickest part of the tapetum (central black area) is located dorso-temporally to the optic nerve disc (white circle). Dots show the periphery of the tapetum covered by the lightly pigmented retinal pigment epithelial layer. Oblique lines show the heavily pigmented retinal epithelial layer without the tapetal tissue. T, temporal.

in aged dogs. It is speculated that the atypical tapetum results from tapetal cell degeneration in addition to congenital hypoplasia of the tapetum. For example, smaller-sized breeds have significantly smaller tapetal area [9]. In this study, the normal tapetum had a wide variety of thickness $(53 \pm 17$ $\mu \mathrm{m})$. The thin normal tapetum would be frequently abnormal at a relatively young age. It has been suggested that tapetal cells may be vulnerable. Several studies have shown selective tapetal cell degeneration following administration of drugs, including a beta-adrenergic blocking agent $\mathrm{SCH}$ 19927 [20], a macroride antibiotic (rosaramicin) [14], an azaride antibiotics (CP 62,993) [8], an aromatase inhibitor (CGS 14796C) [21] and an antipsychotic agent (1192U90) [5]. Furthermore, tapetal cell degeneration may result from malnutrition. Tapetal cells in the dog are packed with long slender rods [13], which are rich in zinc [12, 24, 25]. Zinc is essential for preservation of the structure of normal tapetal rods, because the congenitally abnormal tapetum which lacks zinc in its tapetal rods is not visible in ophthalmoscopy and shows an absence of the regular arrays of tapetal rods [25]. Drugs that chelate zinc cause a reversible tapetal 


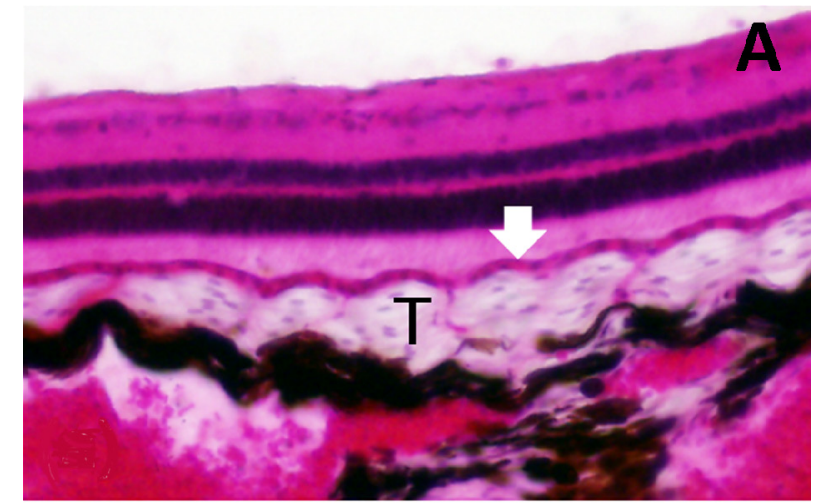

B

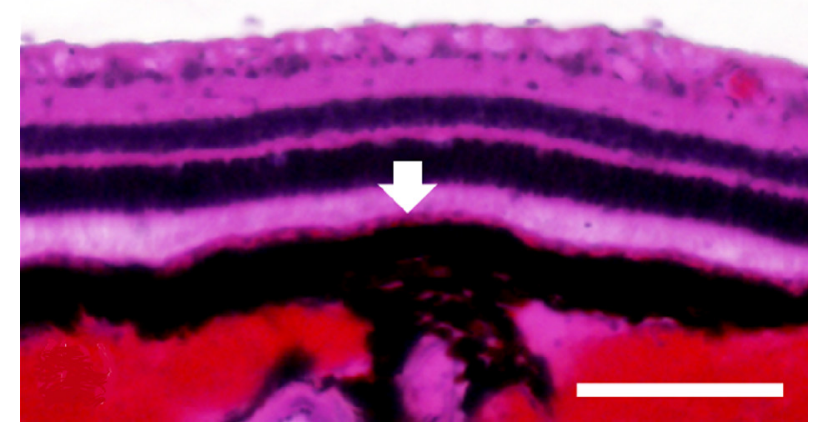

Fig. 5. Histological photographs of Fig. 2C. A, The thickest part of the tapetum $(\mathrm{T})$ is covered by unpigmented retinal pigment cells (arrow). B, Unpigmented retinal pigment epithelial cells (arrow), which normally cover the tapetal tissue, are found in the broad area without tapetal tissue. $\mathrm{Bar}=100 \mu \mathrm{m}$. decoloration in dogs $[8,19]$. Even in human in developed countries, zinc deficiency is common in the elderly, and zinc supplementation delays the progression of age-related macular degeneration and reduces the risk of loss of vision [18]. Zinc deficiency can affect most organ systems in dogs as well [3]. If zinc deficiency is not uncommon in elderly dogs, tapetal cells may gradually degenerate for zinc deficiency with aging. In addition, the tapetum contains very large amount of cysteine [24]. Cysteine, to which zinc readily binds, is necessary for the biosynthesis of glutathione, which is quantitatively the most important antioxidant and radical scavenger. The age-related decrease in the body's cysteine and /or glutathione level plays a causative role in various ageing related degenerative processes [6]. As the age-related decrease in zinc and cysteine may synergistically increase tapetal cell degeneration, there may be a trend toward an increase of tapetal cell degeneration with aging.

\section{REFERENCES}

1. Bellhorn, R. W., Bellhorn, M. B., Swarm, R. L. and Impellizzeri, C. W. 1975. Hereditary tapetal abnormality in the beagle. Ophthalmol. Res. 7: 250-260. [CrossRef]

2. Burns, M. S., Bellhorn, R. W., Impellizzeri, C. W., Aguirre, G. D. and Laties, A. M. 1988. Development of hereditary tapetal degeneration in the beagle dog. Curr. Eye Res. 7: 103-114. [Medline] [CrossRef]

3. Cummings, J. E. and Kovacic, J. P. 2009. The ubiquitous role of zinc in health and disease. J. Vet. Emerg. Crit. Care (San Antonio) 19: 215-240. [Medline] [CrossRef]

4. Diesem, C. 1975. Carnivore sense organs and common integument. pp. 1741-1768. In: Sisson and Grossman's The Anatomy

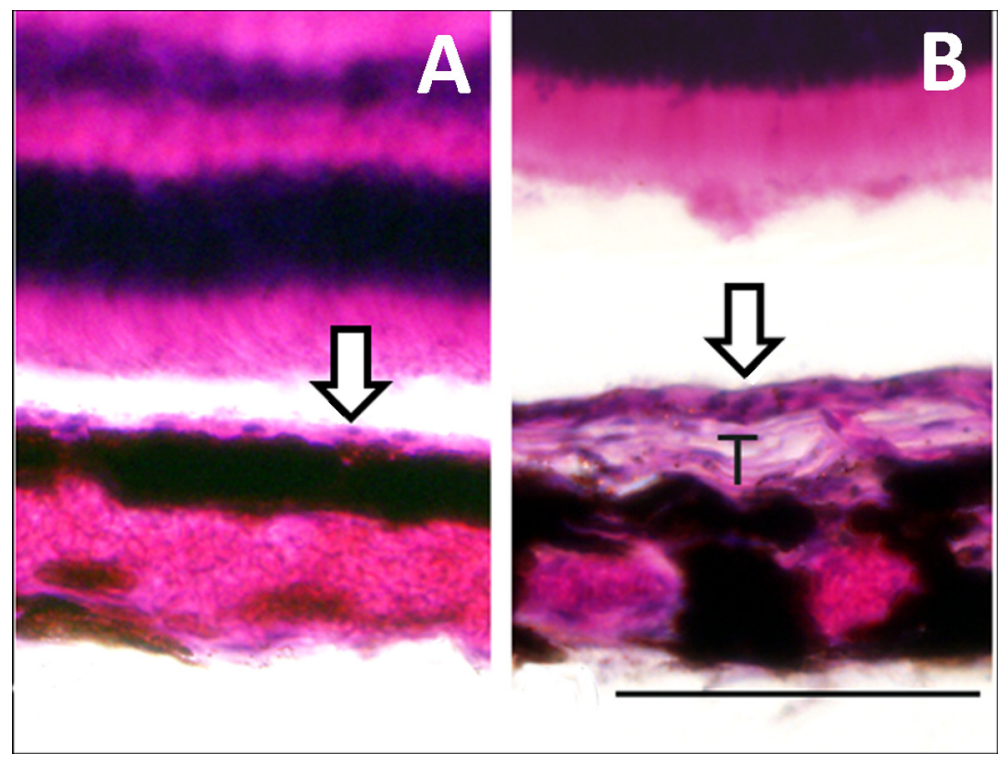

Fig. 6. Histological photographs of Fig. 2D. A, The unpigmented retinal pigment epithelial layers (arrow) are found in the reddish-brown area without the tapetum. B, Although the macroscopic tapetum is not observed, fragmented tapetal tissues (T) are rarely found in the reddish-brown area. Bar $=100 \mu \mathrm{m}$. 
of Domestic Animals, 5th ed. (Getty, R. ed.), WB Saunders, Philadelphia.

5. Dillberger, J. E., Peiffer, R. L., Dykstra, M. J., O’Mara, M. and Patel, D. K. 1996. The experimental antipsychotic agent 1192U90 targets tapetum lucidum in canine eyes. Toxicol. Pathol. 24: 595-601. [Medline] [CrossRef]

6. Dröge, W. 2005. Oxidative stress and ageing: is ageing a cysteine deficiency syndrome? Philos. Trans. R. Soc. Lond., B, Biol. Sci. 360: 2355-2372. [Medline] [CrossRef]

7. Feeney-Burns, L. and Mixon, R. N. 1979. Development of amelanotic retinal pigment epithelium in eyes with tapetum lucidum: Melanosome autophagy and termination of melanogenesis. Dev. Biol. 72: 73-88. [Medline] [CrossRef]

8. Fortner, J. H., Milisen, W. B., Lundeen, G. R., Jakowski, A. B. and Marsh, P. M. 1993. Tapetal effect of an azalide antibiotic following oral administration in beagle dogs. Fundam. Appl. Toxicol. 21: 164-173. [Medline] [CrossRef]

9. Granar, M. I. K. S., Nilsson, B. R. and Hamberg-Nystrom, H. L. 2011. Normal color variations of the canine ocular fundus, a retrospective study in Swedish dogs. Acta Vet. Scand. 53: 13. [Medline] [CrossRef]

10. Heywood, R. 1972. An anomaly of the ocular fundus of the Beagle dog. J. Small Anim. Pract. 13: 213-215. [Medline] [CrossRef]

11. Janssens, G. H. R. R. 2011. Normal variation of the ocular fundus in dogs. Acta Vet. Scand. 53: 193-198.

12. Karcioglu, Z. A. 1982. Zinc in the eye. Surv. Ophthalmol. 27: 114-122. [Medline] [CrossRef]

13. Lesiuk, T. P. and Braekvelt, C. R. 1983. Fine structure of the canine tapetum lucidum. J. Anat. 136: 157-164. [Medline]

14. Massa, T., Davis, G. J., Schiavo, D., Sinha, D. P., Szot, R. J., Black, H. E. and Schwartz, E. 1984. Tapetal changes in beagledogs: II. Ocular changes after intravenous administration of a macrolide antibiotic-Rosaramicin. Toxicol. Appl. Pharmacol. 72: 195-200. [Medline] [CrossRef]

15. Miller, P. E. and Murphy, C. J. 1995. Vision in dogs. J. Am. Vet.
Med. Assoc. 207: 1623-1634. [Medline]

16. Narfstrom, K. and Petersen-Jones, S. 2007. Diseases of the canine ocular fundus. pp. 944-1025. In: Veterinary Ophthalmology, 4th ed. (Gelatt, K. N. ed.), Blackwell Publishing, Oxford.

17. Parry, H. B. 1953. Degenerations of the dog retina. I. Structure and development of the retina of the normal dog. Br. J. Ophthalmol. 37: 385-404. [Medline] [CrossRef]

18. Prasad, A. S. 2003. Zinc deficiency. BMJ 326: 409-410. [Medline] [CrossRef]

19. Sato, S. 1985. Toxic effects on the visual system of diaminodiphenoxybutane, quinine, and ethambutol in conscious dogs. Fundam. Appl. Toxicol. 5: 777-784. [Medline] [CrossRef]

20. Schiavo, D. M., Sinha, D. P., Black, H. E., Arthaud, L., Massa, T., Murphy, B. F., Szot, R. J. and Schwartz, E. 1984. Tapetal changes in beagle dogs. I. Ocular changes after oral administration of a beta-adrenergic blocking agent-SCH 19927. Toxicol. Appl. Pharmacol. 72: 187-194. [Medline] [CrossRef]

21. Schiavo, D. M., Green, J. D., Traina, V. M., Spaet, R. and Zaidi, I. 1988. Tapetal changes in beagle dogs following oral administration of CGS 14796C, a potential aromatase inhibitor. Fundam. Appl. Toxicol. 10: 329-334. [Medline] [CrossRef]

22. Thibos, L. N., Levick, W. R. and Morstyn, R. 1980. Ocular pigmentation in white and Siamese cats. Invest. Ophthalmol. Vis. Sci. 19: 475-486. [Medline]

23. Tjälve, H. and Frank, A. 1984. Tapetum lucidum in the pigmented and albino ferret. Exp. Eye Res. 38: 341-351. [Medline] [CrossRef]

24. Wen, G. Y., Sturman, J. A., Wisniewski, H. M., MacDonald, A. and Niemann, W. H. 1982. Chemical and ultrastructural changes in tapetum of beagles with a hereditary abnormality. Invest. Ophthalmol. Vis. Sci. 23: 733-742. [Medline]

25. Wen, G. Y., Sturman, J. A. and Shek, J. W. 1985. A comparative study of the tapetum, retina and skull of the ferret, dog and cat. Lab. Anim. Sci. 35: 200-210. [Medline]

26. Wyman, M. and Donovan, E. F. 1965. The ocular fundus of the normal dog. J. Am. Vet. Med. Assoc. 147: 17-26. [Medline] 